\title{
Use of analgesia in severe pain in the accident and emergency department
}

\author{
M. REICHL \& G. G. BODIWALA \\ Accident and Emergency Department, The Leicester Royal Infirmary, Leicester, England
}

\section{SUMMARY}

The adequate management of severe pain in accident and emergency departments depends on knowledge of the pharmacology of analgesic drugs. To evaluate such a knowledge a study by questionnaire was conducted.

Fourteen accident and emergency departments participated and one hundred senior house officers answered the questionnaire. A large percentage of the respondents would use an inappropriate route of administration (intramuscular $50 \%$ rather than intravenous $50 \%$ ), some would use an inappropriate drug and often wait too long $(90 \mathrm{~min}$ ) before giving a further dose of analgesic should the patient continue to be in severe pain after the initial dose.

These results suggest that (a) there is need for further teaching on pain relief at medical schools, (b) casualty officers need to be taught about analgesia when they start working in accident and emergency departments, and (c) it may be beneficial for accident and emergency departments to have an analgesic policy.

\section{INTRODUCTION}

One of the functions of an accident and emergency (A\&E) department is to reduce pain and suffering in acute admissions (Baskett $\&$ Zorab, 1975). Some evidence exists that under-treatment of pain occurs on acute medical wards (Marks \& Sachar, 1973) and on burns units (Perry \& Heidrich, 1982; Perry, 1984). These papers show that the main reason for undertreatment is the physicians lack of knowledge of achieving adequate analgesia combined with their fear of causing drug overdose. The authors decided to find out if the same would be true in A\&E departments. A study was conducted by questionnaire which was distributed to $30 \mathrm{~A} \& \mathrm{E}$ departments in the United Kingdom. The analysis of the results and comments on how management of pain in the A\&E departments could be improved are presented. 


\section{METHODS}

A questionnaire was constructed, which was aimed at the senior house officers (SHOs) working in the A\&E departments. It consisted of seven questions on hypotheticap common clinical situations to determine which analgesic drug, dose and the route of administration the doctor would choose for the given situation. These questions are summarised in Table 1.

The questionnaire also enquired how the SHOs would react should their patient with $\frac{\frac{\sigma}{5}}{\frac{5}{D}}$ severe orthopaedic trauma still be in pain $20 \mathrm{~min}$ after the initial dose of analgesic drugs $\stackrel{\mathbb{\Omega}}{\varrho}$ The results were collated and analysed.

Table 1 Questionnaire for SHOs in accident and emergency: Which analgesics would you give in the्ठ following hypothetical situations?

Drug Dose Route

1. A 17-year-old male with a compound comminuted fracture of the tibia and fibula

2. A 45-year-old male with a 'mangled' right hand

3. A 25 -year-old female with a $40 \%$ partial thickness burn

4. A 2-year-old male (weighing $12 \mathrm{~kg}$ ) with a superficial scald

5. A 40-year-old female with renal colic

6. A 70-year-old female with severe chest pain/M.I.

7. Your flying squad is called to an accident where you find a 60 -year-old female trapped in a car complaining of severe pain in both legs and chest (patient was not knocked out)

\section{RESULTS}

The questionnaire was distributed to $30 \mathrm{~A} \& \mathrm{E}$ departments. These were chosen on the basis that they all have a full-time consultant in A\&E medicine in charge. Three departments indicated that they did not wish to participate.

Of the remaining 27, completed questionnaires were received from 14. Excluding incorrectly filled in questionnaires, we were able to analyse the response from $100 \mathrm{SHO} \overline{\mathrm{S}}$ from these departments. The majority of the respondents were half way through their 6-month appointment.

One hundred questionnaires were analysed. For convenience, morphine, papaveri tum and diamorphine were combined into a single analgesic category and are termed్ strong opiates. This is justified because in equi-analgesic doses the actions and occurrence of side effects are similar (Gilman et al., 1980). The results were analysedf according to the type of analgesic used, its dosage and the route of administration. 
Table 2 Analgesics prescribed by number of SHOs for given conditions

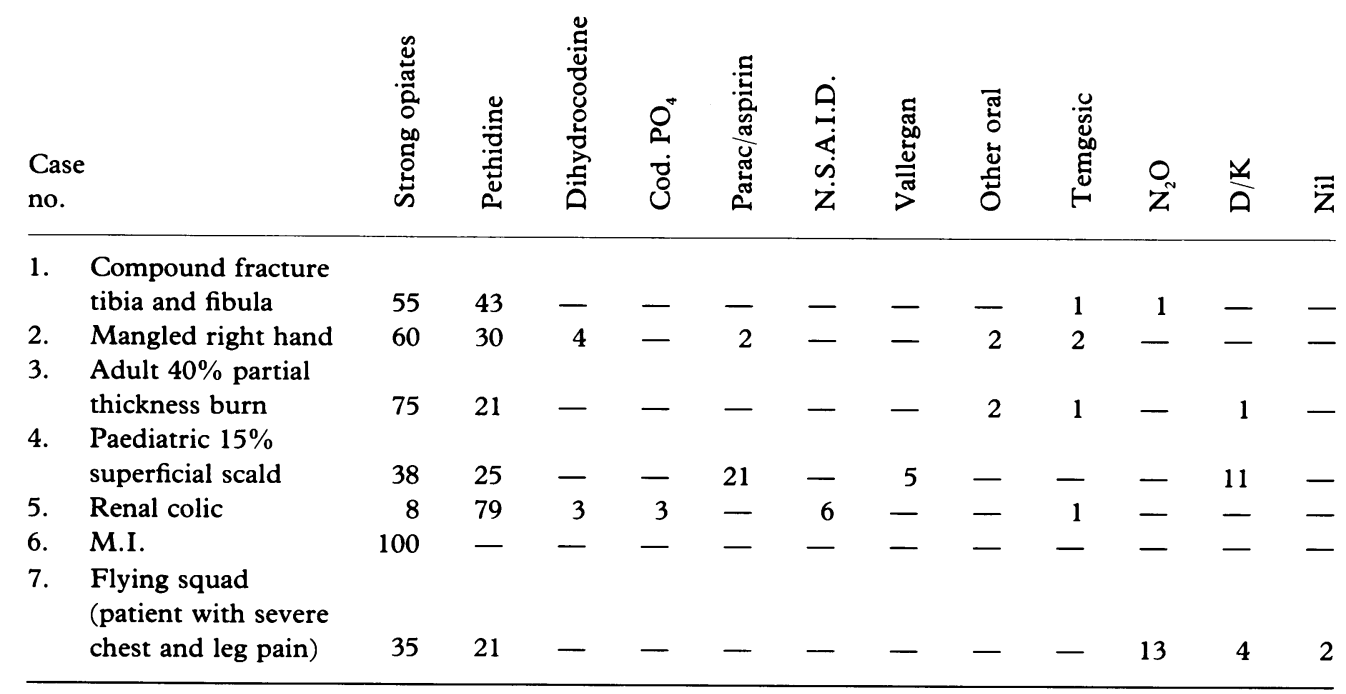

The respondents were divided mainly between the use of strong opiates $42 \%$ and pethidine $30 \%$. However, the use of these analgesics varied greatly between individual situations. All other analgesics (Table 2) were used only rarely.

Only the dosage of the strong opiates and pethidine were analysed. There was a great degree of agreement in the doses used. The majority would use $75 \mathrm{mg}$ of pethidine or $10 \mathrm{mg}$ of morphine in adults, and $12.5 \mathrm{mg}$ of pethidine or $2 \mathrm{mg}$ of morphine in a $12 \mathrm{~kg}$ child. However, a few doctors would have prescribed analgesics in excessively high dosage.

The routes of administration in the various cases are listed in Table 3. From this, it is evident that in the majority of situations less than $50 \%$ of doctors would administer analgesics intravenously (IV). The rest would use other routes of which intramuscular

Table 3 Route of administration of analgesics preferred by SHOs for given conditions

\begin{tabular}{|c|c|c|c|c|c|c|c|c|c|}
\hline \multicolumn{2}{|c|}{$\begin{array}{l}\text { Case } \\
\text { no. }\end{array}$} & \multirow[t]{2}{*}{ I.V. } & \multirow[t]{2}{*}{ I.M. } & $\mathrm{O}$ & $\mathrm{S} / \mathrm{L}$ & Inhal. & \multirow[t]{2}{*}{ Block } & \multirow[t]{2}{*}{$\mathrm{D} / \mathrm{K}$} & \multirow[t]{2}{*}{ Nil } \\
\hline 1. & $\begin{array}{l}\text { Fracture tibia and } \\
\text { fibula }\end{array}$ & & & - & 1 & 1 & & & \\
\hline 2. & Hand injury & 35 & 55 & 8 & 2 & - & - & - & - \\
\hline 3. & Adult burn & 52 & 44 & 2 & 1 & - & - & 1 & - \\
\hline 4. & Paediatric burn & 30 & 33 & 26 & - & - & - & 11 & - \\
\hline 5. & Renal Colic & 24 & 74 & - & 1 & - & - & - & 1 \\
\hline 6. & M.I. & 91 & 9 & - & - & - & - & - & - \\
\hline 7. & Squad & 36 & 22 & - & - & 13 & - & 1 & 4 \\
\hline
\end{tabular}


(IM) is the commonest. The significant exception was myocardial infarction when 91 恩 of the doctors would use the IV route. Oral analgesics would be fairly frequently especially in the treatment of a child with burns where the oral route would be used b\% $27 \%$ of the SHOs.

Finally, Table 4 summarises the answer to the question, "What would you do if patient with a compound comminuted fracture of the-tibia and fibula was still in pai $20 \mathrm{~min}$ after the initial dose of analgesia?'

Only 76 out of the 100 answered this question. Of these, $39(55 \%)$ would prescribe $\frac{\overline{\bar{q}}}{\bar{q}}$ further dose of the same drug immediately. However, $28(38 \%)$ would wait longem before giving more analgesia.

Table 4 Pain 20 min. after administration of the first dose of analgesics

\begin{tabular}{|c|c|c|c|c|}
\hline & \multicolumn{4}{|c|}{ No. of SHOs } \\
\hline Give the same drug immediately & \multicolumn{4}{|c|}{39} \\
\hline Give other drug immediately & \multicolumn{4}{|c|}{6} \\
\hline Wait & \multicolumn{4}{|c|}{27} \\
\hline Did not respond & \multicolumn{4}{|c|}{28} \\
\hline \multicolumn{5}{|l|}{ If wait } \\
\hline Wait further (min) & 30 & 45 & 60 & 120 \\
\hline Number of SHOs & 7 & 6 & 9 & 3 \\
\hline
\end{tabular}

\section{DISCUSSION}

Our personal experience and some limited epidemiology (Marks \& Sachar, 1973; Perr \& Heidrich, 1982; Perry, 1984) points to the fact that a significant number of patients with acute painful conditions are under-treated with analgesics. To determine what paro is played by the lack of knowledge on behalf of the prescribing doctor, we constructed questionnaire which was answered by 100 SHOs from various A\&E departments in the United Kingdom.

The results show that there are several areas where an improvement could b achieved.

\section{Drugs}

In trauma, morphine is the best analgesic drug (Smee \& Crochard, 1981). However there is little to choose between the strong opiates or pethidine for the treatment of severe pain. 
As shown in Table 2, most of the respondents would use either strong opiates or pethidine. Unfortunately, a few would use a totally inappropriate drug. This seems to be the commonest in the management of a child when $21 \%$ would use a mild analgesic (aspirin or paracetamol) and $5 \%$ would use Vallergan which is a sedative with no analgesic property.

Very few SHOs were prepared to use nitrous oxide $\left(\mathrm{N}_{2} \mathrm{O}\right)$, despite it being a safe and non-toxic agent (McCarthy, 1985; Clarke et al., 1977) with an excellent analgesic effect. In two recent studies, when Entanox $\left(50 \% \mathrm{~N}_{2} \mathrm{O} / 50 \% \mathrm{O}_{2}\right)$ was used in trauma, over $90 \%$ of the patients experienced partial or complete relief of pain (Thal et al., 1979; Stewart et al., 1983).

\section{Doses}

Because of the different patient responses it is difficult to say what a correct dose should be in any one situation. However, the average dose used by most of our respondents tended to be at the lower limit recommended in the literature (Gourlay \& Cousins, 1984). However, $15 \%$ of the respondents appended a comment that they would titrate the dose of analgesics to the patients requirement.

\section{Route of administration}

In emergency situations, analgesic drugs can be administered via all the usual routes. However, some routes may be more appropriate than others. In 1947, Beecher indicated that, in trauma, opiates should be given intravenously. This is also stressed more recently by Smee et al. (1981). IV rather than IM doses of opiates achieve a more rapid and predictable absorption of the drug, which means an earlier onset of action (Gourlay \& Cousins, 1984). It also avoids accumulation of the drug in poorly perfused muscle with obvious potentially dangerous effects (Greenblatt \& Kock-Wesser, 1976). The majority of severely injured patients will have intravenous lines and it is practical to use these for administering analgesia.

The effectiveness and safety of morphine given intravenously in trauma was well demonstrated by the Australian Medical Team (Gourlay \& Cousins, 1984).

A similar opinion was expressed by the doctors involved in the Falklands campaign (Williams et al., 1983). They administered IV morphine in small frequent doses according to the severity of pain. They did not encounter complications such as respiratory depression and used this method of analgesia in all situations including chest injuries.

Although the advantages of the IV route are well described in the literature, on average only half of the respondents would use this route. The rest would preferentially give analgesics for severe pain intramuscularly or even orally.

The oral route of administration has no role in the management of severe pain secondary to acute trauma. Many such patients develop abdominal ileus, often accompanied by vomiting, therefore, even if the patient is able to take oral medication, it is unlikely that any drug would be absorbed from the gastrointestinal system. 
Action if no response

As shown in Table 4, some 37\% (27 out of 72 ) of the respondents would wait before administering further doses of analgesia despite the fact that the patient was still in pairọ What is even more surprising is that of these 27 doctors, 14 would wait at least a furth hour before giving more analgesia. This means that $20 \%$ of doctors in our sample would leave patients for at least $90 \mathrm{~min}$ after arriving in the $\mathrm{A} \& \mathrm{E}$ department. That is, despits the fact that it has been shown in the Falklands (Williams et al., 1983) that giving sma incremental doses of morphine intravenously to achieve full pain relief is quite safe. $\stackrel{\mathbb{\Phi}}{\unrhd}$

\section{CONCLUSION}

If we extrapolate from our sample, it appears that the majority of patients with severi pain seen in the A\&E departments will get suboptimal pain relief. The main problem is that opiates are not given intravenously and the dose is not repeated early enough if the patient is still in pain. The problem seems to be especially common in the management of pain in children.

There is a high degree of uniformity in the treatment of pain such as renal colic and myocardial infarction. Management of these two conditions is usually well covered ir many medical text books and in teaching sessions at medical school. However, as there is no such uniformity in other conditions it is likely that the problem of analgesi trauma is not adequately taught.

We recommend that there should be some teaching on the use of analgesics in trat by medical schools and at the clinical level for SHOs in the A\&E departments. It mal also be beneficial to have a departmental policy on analgesia which the SHOs could refe to.

\section{REFERENCES}

Baskett P. J. \& Zorab J. S. M. (1975) Priorities in the immediate care of roadside and other traumati⿺ casualties. Anaesthesia 30, 80-7.

Beecher H. W. (1947) Resuscitation and Anaesthesia for Wounded Man. The Management of Traumatic Shoc鹿 Springfield, Illinois, C. C. Thomas.

Clarke R. S. J., Harcus A. W., Smith R. B. \& Whittle B. A. (eds) (1977) Pain. Edinburgh, Churchi 유 Livingstone.

Gilman A. G., Gooch M. L. S. \& Gilman A. (1980) The Pharmacological Basis of Therapeutics, Sixth edition. London, Macmillan.

Gourlay G. K. \& Cousins M. J. (1984) Strong analgesics in severe pain. Drugs 27, 79-81.

Greenblatt D. J. \& Kock-Wesser J. (1976) Intramuscular injection of drugs. New England fournal of Medicin 295, 542-5.

McCarthy K. (1985) Pain. London, Update Publications.

Marks R. M. \& Sachar E. J. (1973) Under-treatment of medical in-patients with narcotic analgesia. Annals Internal Medicine 78, 173-87.

Perry S. W. (1984) Under-medication for pain on a burns unit general hospital. Psychiatry 6, 308-16. 
Perry S. \& Heidrich G. (1982) Management of pain during debridment: a survey of the U.S. burn units. Pain 13, $167-80$.

Smee W. O. \& Crochard A. (1981) Trauma Care. London, Academic Press.

Stewart R. D., Paris P. M., Stoy B. S. \& Cannon G. (1983) Patient-controlled inhalational analgesia in the pre-hospital care: a study of side-effects and feasibility. Critical Care Medicine 11, 851-5.

Thal E. R., Montgomery S. J., Atkins J. M. \& Roberts B. G. (1979) Adjunctive aid for emergency medical care systems. Fournal of the American Medical Association 242, 2418-9.

Williams J., Riley T. R. D. \& Moody R. A. (1983) Resuscitation experience in the Falkland Islands campaign. British Medical fournal 9i, 775-7.

Received 23 fune 1986; accepted 2 September 1986 